\title{
Comparative Analysis of Original AODV and AODV-DOR Routing Protocols in Mobile Ad-hoc Networks
}

\author{
Shyam Singh Rajput \\ CSE, dept. \\ ABV-IIITM, Gwalior
}

\author{
Vinod Kumar \\ CSE, dept. \\ ABV-IIITM, Gwalior
}

\author{
Kalka Dubey \\ CSE, dept. \\ ABV-IIITM, Gwalior
}

\begin{abstract}
An ad hoc network is a group of movable wireless nodes that wants to share or exchange the information without any fixed infrastructure or centralized control. Ad hoc network is a selfconfiguring network of movable devices which may be connected by a wireless links. The union of these mobile devices forms an arbitrary topology. Due to very high dynamic environment nature of MANET, routing is a very crucial task for measuring the performance. A number of protocols have been familiarized to be rectified the routing mechanism which can find the path between any source host to destination host within the network. This paper focuses on the most popular and widely used Ad hoc On-demand Distance Vector (AODV) reactive MANETs routing protocol with two different flag settings. This paper provides the performance (Average End to End Delay and Packet Delivery Ratio) comparisons of original AODV and AODV-DOR (AODV with destination only reply) in different network conditions. For our simulation we used discrete event simulator known as Network Simulator version 2.35
\end{abstract}

\section{General Terms}

Performance comparisons, MANETs, AODV-DOR

\section{Keywords}

MANETs, AODV, AODV-DOR, Reactive routing Simulation

\section{INTRODUCTION}

Mobile Ad Hoc Network (MANET) is a group of independent mobile nodes or devices that wish to share or exchange the information which is infra structureless and doesn't have any predetermined set-up of available links. It is a self-configuring and self-organizing multi hop network of wireless nodes, where the network structure's changes dynamically $[1,10]$. This happens mainly because the nodes are mobile in nature [2]. The nodes are independent to move anywhere randomly and form the network structure arbitrarily. Therefore, the topology of the wireless network may change quickly and unpredictable. This wireless Ad-Hoc network is also known as Mobile Ad-Hoc multi-hop wireless network and it is a collection of wireless mobile devices creating a mutable network without the help of any established infrastructure or centralized administration. Mobile Ad-Hoc networks (MANETs) have properties like dynamic in nature and muti hop rapid changing topology $[3,4,11]$. These types of networks are used to provide communication capabilities in those types of areas where communication range is fixed and no infrastructure exist. MANETs can also be used to allow sharing the information between the nodes to form a mutable and temporary network. It is used in Military communication and operations, Automated battlefields, Search and rescue operation in remote area, Emergency operations, Disaster recovery, Vehicular services, Business transaction, Ecommerce, Conferences and meeting rooms, Personal area networks (PAN), Virtual classrooms, Universities and campus settings. The scope of the ad-hoc network is also associated with the Bandwidth constrained, Energy constrained operations, Dynamic topology changes, Hidden terminal problem, Limited physical security, Broadcasting of the wireless medium, Mobility-induced packet losses, and Loss of packets because of errors in transmission attention because of several potential civilian and military applications. In MANET multi-hop routing is used to provide network connectivity instead of static network infrastructure. Routing is one of the main crucial problems in MANETs for sending data packets from one mobile node to other nodes in the network. Many routing protocols have been proposed for mobile ad-hoc networks. It can uses AODV in two different mode first is named as Original AODV in which intermediate node can also send the RREP (route reply) if they have the fresh enough route to the destination and second is AODVDOR (AODV with destination only reply mode) in this mode of AODV only the intended destination can send the RREP message. In this paper we simulate AODV with these two different mode and analysis the performance of these two, AODV and AODV-DOR with different network simulation parameters such as number of connection, pause time etc.

\section{CLASSIFICATION OF AD-HOC ROUTING PROTOCOLS}

The ad-hoc routing protocols are classified as follows

\subsection{Table Driven Routing Protocols}

These types of protocols are also known as proactive protocols in which they store all the routing information before it is needed. All the nodes in the network maintain routing information to each and every other node in the network. Generally, routing table contains all the routing information and it periodically updates as soon as the network topology changes. The only advantage of using this protocol is that the routes to any arbitrary destination are always available with minimum initial delay. The overhead of route discovery is eliminated here. Examples protocols are AWDS, OLSR, and DSDV etc.

\subsection{On Demand Routing Protocols}

These types of protocols are also known as reactive protocols in which they don't maintain the routing information or any other routing behavior at any node if there is no communication. These protocols use the routing information when it is actually required. If a node wants to communicate with any other node,first it initiate a route request message in 
an on-demand manner and then sends the packet to that node after connection establishment. This route discovery process starts with the flooding the route request message throughout the network. The only disadvantage of using this protocol is high latency time in route discovery process and excess flooding lead to network clogging. Examples protocols are AODV, DSR, ABR and TORA.

\subsection{Hybrid Protocols}

This protocol combines the advantages of both on demand routing protocol and table-driven protocol approaches. In hybrid protocols initially the routing is setup with some prospected routes and then completes the demand by reactive flooding. Example protocols are OORP, CBRP, and ZRP etc.

\section{Ad-HOC ON DEMAND DISTANCE VECTOR (AODV)}

Ad hoc On-Demand Distance Vector (AODV) Routing is a routing protocol which is designed and used for mobile and other wireless adhoc networks[12]. It is a reactive type routing protocol so it establishes a connection between a sender and receiver only when a demand is needed. The protocol provides dynamic multi hop routing. In this protocol the routes establish quickly for new destination on demand. The source node and intermediary nodes do not maintain the routing information for destination node if it is out of active communication range. When there is a need then only routes are created. The protocol does not require the broadcast of periodic routing updates. AODV protocol has two phases i) route discovery process and ii) route maintenance process. Route discovery process uses two types of messages first is Route Request (RREQs) and Route Reply (RREPs) messages. These routing messages only know about the source and the destination. When a source wants to communicate with a node, first it has to establish a route up to destination. After that the source node broadcast a route request message to all it neighbors to find the shortest path. This route request message contains Source IP Address, Destination IP Address, Source Sequence Number, Destination Sequence Number, route request broadcast ID and hop count. The difference between AODV and other on-demand routing protocols is that it uses sequence number to find a valid and fresh path up to destination. These sequence number is used to prevent the loop, fast convergence and route freshness. This sequence number also helps AODV to avoid "count to infinity" problem. A node increases its sequence number when it wants to send some control messages like RREQ, RREP to destination. Every node in the network updates the routing table information about the latest sequence number. This routing table updates only some field related to some specific node. When any node receives RREP, RREQ or RRER, its routing table is again updated. Hop count describes the number of hops between the source and the destination. When some nodes receive the RREQ message from the source node, they build up the inverse path backwards to that requesting node. When intermediate nodes got the RREQ message they simple forward it up to the destination node. At destination node the destination sequence number is greater than or equal to that RREQ. Now this node discards the route request message and replies back to the sender node with RREP.
Suppose the intermediate node got the RREQ message with 'D' flag (destination only flag) set, it simply forward the RREQ packet because when ' $D$ ' flag is set only the intended destination can send the RREP packet. But suppose if intermediate node receives route request message with ' $G$ ' flag set, it must send RREP only to the destination node. RREP message consists Destination Sequence Number, Source IP Address, Destination IP Address and Lifetime. When the source node got the route reply, it creates a path to the destination and sends the data packet forward to the path setup. Route maintenance has been done via two distinct messages. One is Hello and other is Route Error (RRER) messages. In route maintenance process each node in the network flooded the Hello messages to check the connectivity to its neighbor nodes. If all neighbor nodes receive these Hello messages this proves the existence of the active route towards the sender of the message. But if some node does not get the Hello message from a neighbor node under some time duration then it finds out that the route to the neighbor node has been damaged and produces a Route Error (RRER) message. RRER represents those destinations which are not reachable, their destination sequence number and IP address. To indicate about the path breakage news, every node for each routing table field carry a precursor list that contains the IP address of some defined set of neighboring nodes. While receiving RRER, every predecessor node effectively deleting all the paths that using the broken link. Besides this all routing messages, the sender uses the route reply acknowledge (RREP-ACK) message and send it to the receiver node in order to get a response to RREP message with 'A' bit set. This gives the confirmation message to the receiver of RREQ that the link using is bidirectional.

\section{MOBILE AD-HOC NETWORK PERFORMANCE METRICS}

Performance of the Original AODV (Intermediate node can also send RREP packet) and AODV-DOR (only the destination can send RREP packet) are evaluated using the following metrics

\subsection{Average End to End Delay}

The Average End to End delay includes all delay such as buffering at the time of route discovery, queuing delay at the interface queue, delays caused by retransmission at the MAC layer, and transmission and propagation times. It can be defined as:

Average End to End Delay $\left(\mathrm{T}_{\text {avg }}\right)=\frac{1}{p_{r} \sum_{j=1}^{n}\left(R_{j}-S_{j}\right)}$

Where $P_{r}$ is the total number of successfully received packets at destination, $j$ is unique packet identifier, time at which a packet with unique id $j$ is received is denoted by $R_{j}$, time at which a packet with unique id $j$ is sent is denoted by $S_{j} . T_{a v g}$ is measured in ms. For high performance It should be less. 


\subsection{Packet Delivery Ratio}

Packet Delivery Ratio is the ratio of total packet received to total packet sent. In another word the ratio of the number of data packets successfully received at destination to the packet generated by CBR traffic sources.

\section{SIMULATION AND PERFORMANCE ANALYSIS}

The simulations were performed using widely used simulator tool NS2 for simulation [9]. Network Simulator (NS2) is a discrete-event driven simulator tool used by researchers for simulating routing protocols over wired and wireless. This paper uses the NS2.35 for evaluate the performance of Original AODV and AODV-DOR with different network parameters like maximum number of possible connections, numbers of mobile nodes and pause time etc.

\begin{tabular}{|c|c|}
\hline Simulator & NS2(v-2.35) \\
\hline Simulation Time & $600 \mathrm{sec}$ \\
\hline Number of nodes & 50 \\
\hline Area Size & $1000 \mathrm{~m}^{*} 1000 \mathrm{~m}$ \\
\hline Transmission Range & $250 \mathrm{~m}$ \\
\hline Maximum Speed & $0-20 \mathrm{~m} / \mathrm{s}$ \\
\hline Maximum Number of connection & $5,10,15,20,25$ \\
\hline Application Traffic & CBR \\
\hline Packet Size & 512 bytes \\
\hline Traffic Rate & 4 packet/sec \\
\hline Node Mobility Model & Random Way-point Model \\
\hline
\end{tabular}

Table 1 Simulation Parameters

In simulation, this paper compares Original AODV and AODV-DOR in terms of average end to end delay and packet delivery ratio. We consider five different scenarios for both performance metrics (average end to end delay and packet delivery ratio) to analyze the simulation result. In first scenario, take maximum number of connections are equals to five, in second scenario maximum numbers of connections are equals to ten and similarly in the fifth scenario maximum numbers of connections are equals to 25 but in all scenarios in order to analyze the effect of mobility pause time is varied from 0 seconds to 600 seconds . Each node remains stationary for the time equal to pause time seconds before moving to random destinations. With pause time 0 seconds the mobility is high. Each node moves uninterrupted. A pause time equal to length of simulation (in this simulation we took 600 seconds) corresponds to no motion. The simulation results are shown in the following section in the form of column graphs. The performance of Original AODV and AODV-DOR is compared in terms of "pause time vs average end to end delay" and "pause time vs packet delivery ratio "with different numbers of network connections.

Figure 1, 2, 3, 4, and 5 highlights the relative performance of Original AODV and AODV-DOR protocols for average end to end delay with varying pause time $(0,100,200,300,400,500,600 \mathrm{sec})$ in the presence of the maximum numbers of connections are equals to $5,10,15,20$, and 25 respectively.

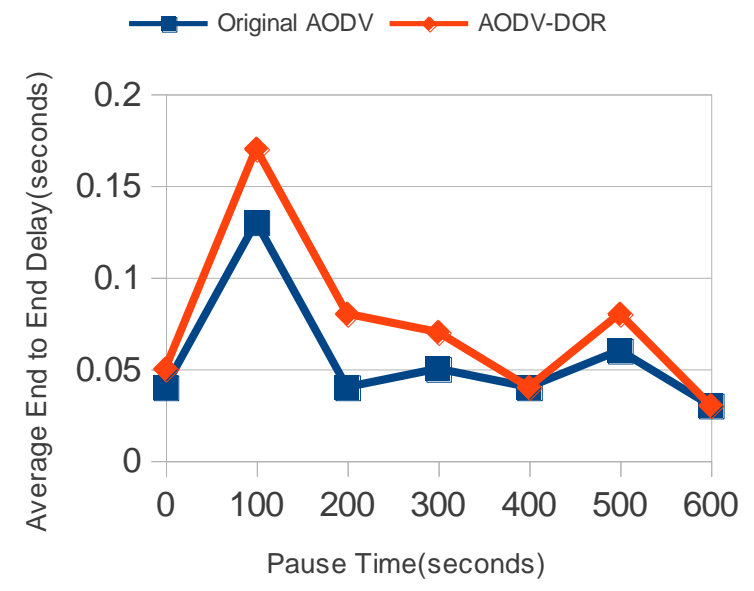

Figure 1 Pause Time vs Average End to End Delay (Maximum number of Connections $=5$ )

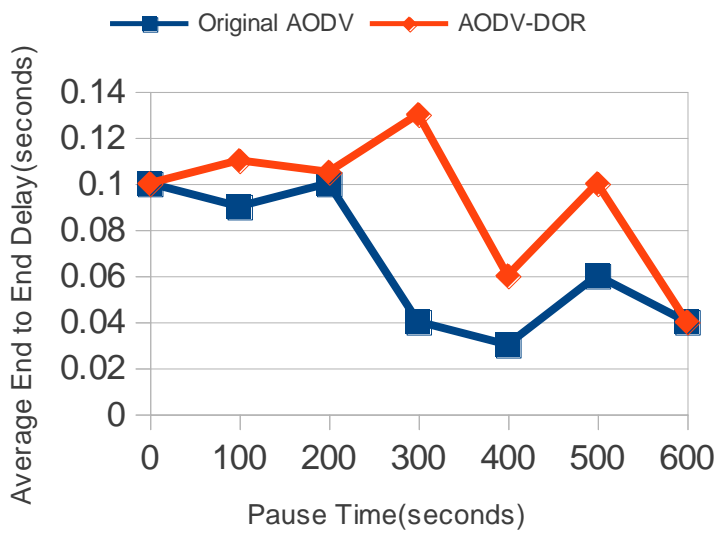

Figure 2 Pause Time vs Average End to End Delay (Maximum number of Connections $=10$ )

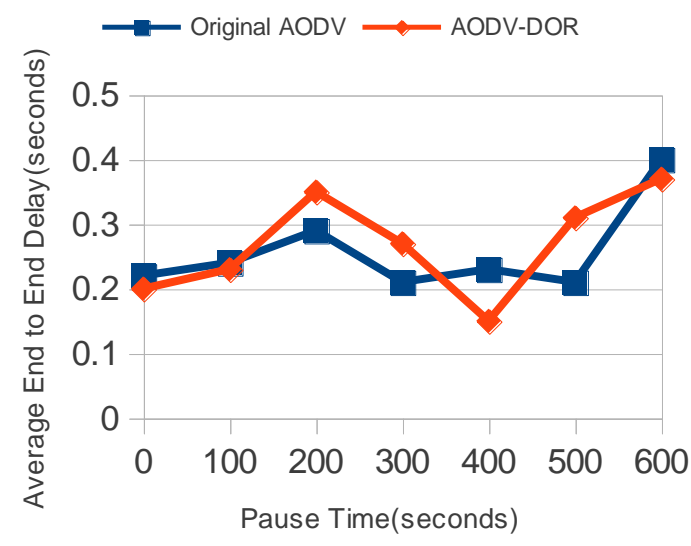

Figure 3 Pause Time vs Average End to End Delay (Maximum number of Connections $=15$ ) 
Figure 4 Pause Time vs Average End to End Delay (Maximum number of Connections $=20$ )

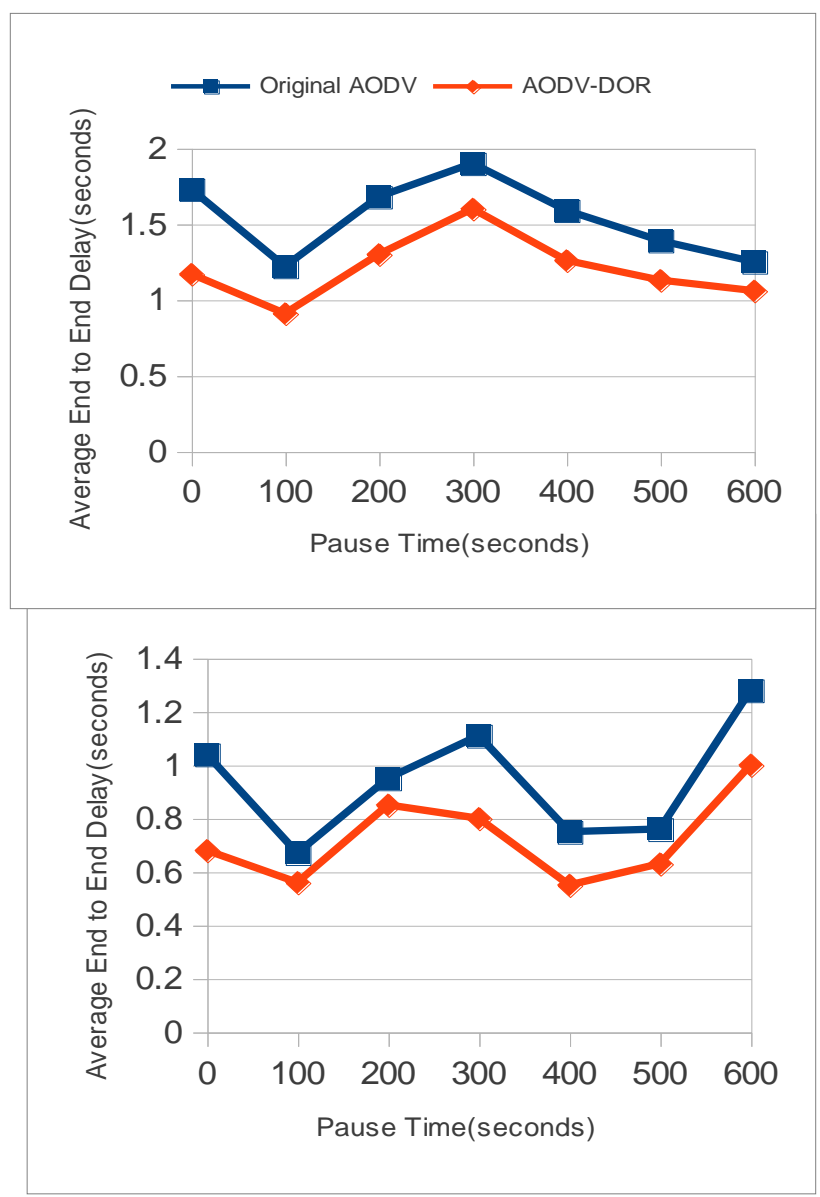

Figure 5 Pause Time vs Average End to End Delay (Maximum number of Connections $=25$ )

Figure 6,7, 8, 9, and 10 highlights the relative performance of Original AODV and AODV-DOR protocols for packet delivery ratio with varying pause time $(0,100,200,300,400,500,600 \mathrm{sec})$ int the presence of the maximum number of connections are equals to $5,10,15,20,25$ respectively.

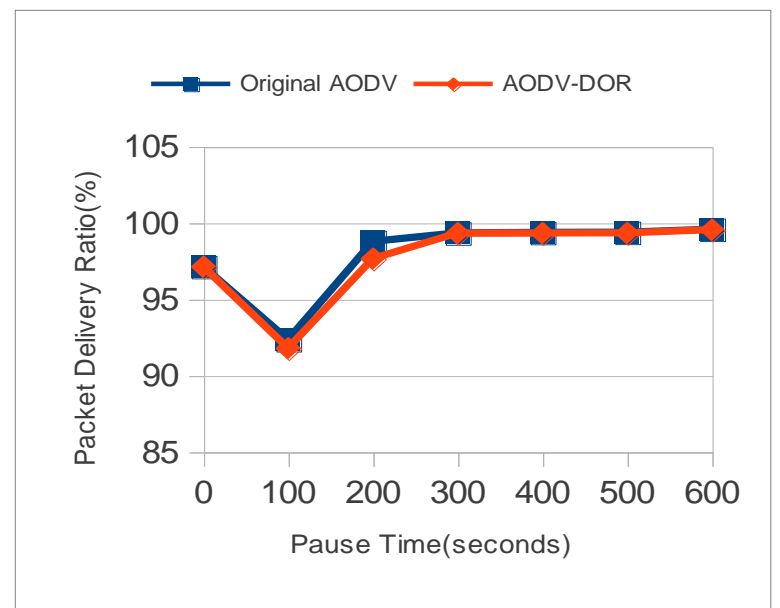

Figure 6 Pause Time vs Packet Delivery Ratio(

Maximum number of Connections $=5$ )

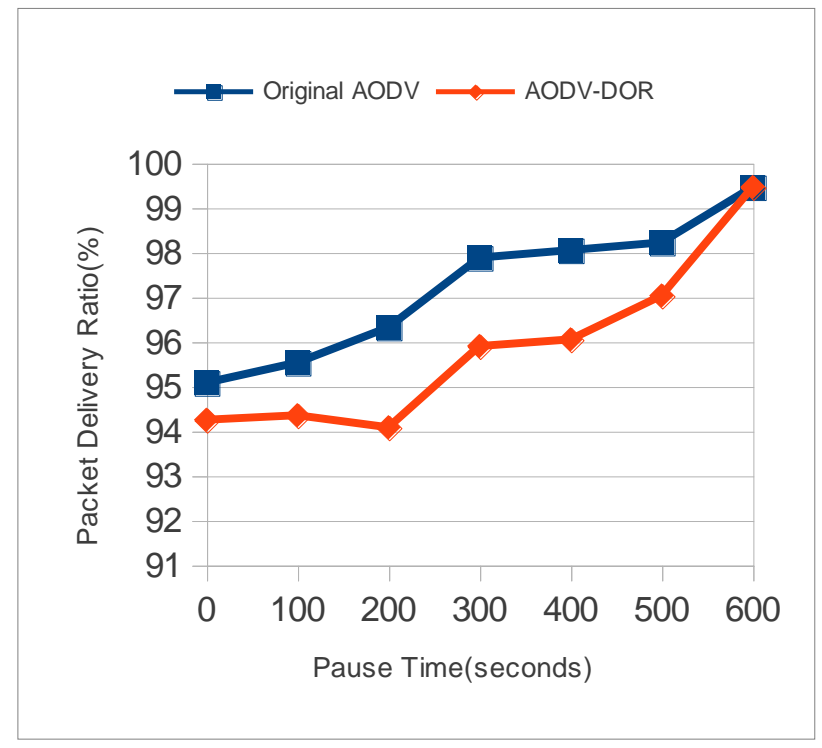

Figure 7 Pause Time vs Packet Delivery Ratio( Maximum number of Connections $=10$ )

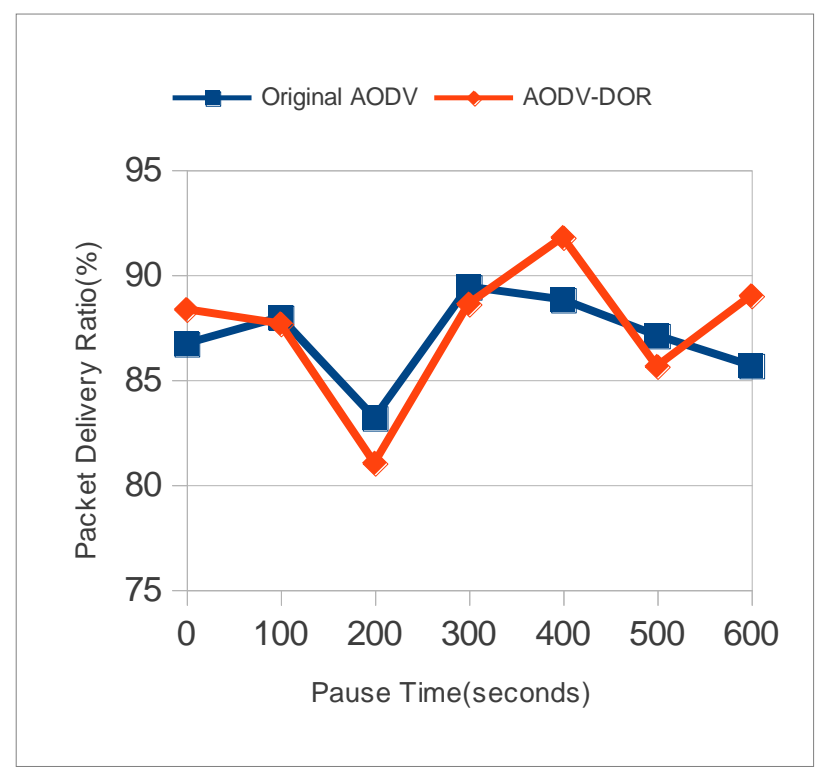

Figure 8 Pause Time vs Packet Delivery Ratio( Maximum number of Connections $=15$ ) 


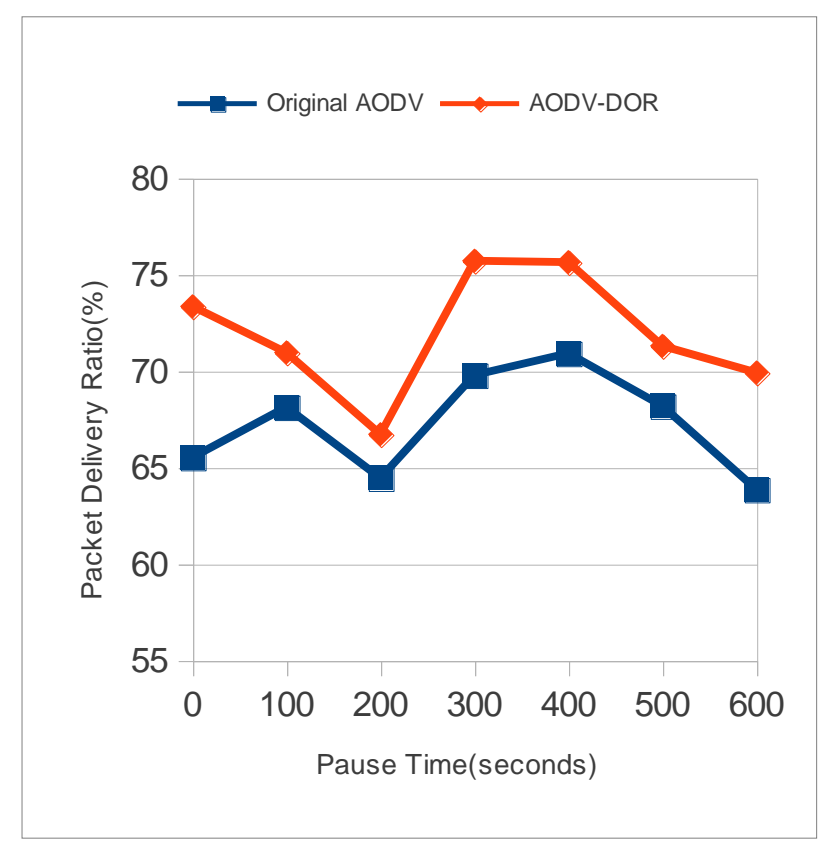

Figure 9 Pause Time vs Packet Delivery Ratio( Maximum number of Connections $=20$ )

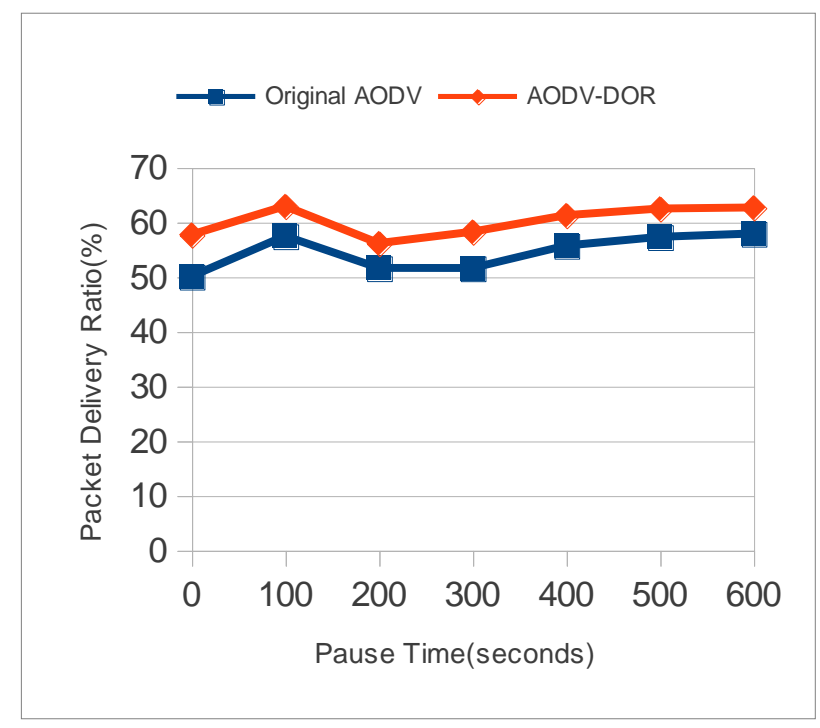

Figure 10 Pause Time vs Packet Delivery Ratio( Maximum number of Connections $=25$ )

In Table 2 shows the best performing protocol in different conditions.

Table 2 Best Performing Protocol

\begin{tabular}{|l|l|}
\hline Parameters & $\begin{array}{l}\text { Best Performing } \\
\text { Protocol }\end{array}$ \\
\hline AverageE2E(Max.no of conns $<=10)$ & Original AODV \\
\hline
\end{tabular}

\begin{tabular}{|l|l|} 
Average E2E(Max.no of conns =15) & OriginalAODV/ \\
AODV-DOR \\
\hline Average E2E(Max.no of conns $>=20)$ & AODV-DOR \\
\hline PDR(Max.no of conns $<=10)$ & Original AODV \\
\hline PDR(Max.no of conns $=15)$ & $\begin{array}{l}\text { Original } \\
\text { AODV/AODV- } \\
\text { DOR }\end{array}$ \\
\hline PDR(Max.no of conns $>=20)$ & AODV-DOR \\
\hline
\end{tabular}

\section{CONCLUSIONS}

In this paper, we examine the performance differences of Original AODV and AODV-DOR routing protocol for mobile ad-hoc networks in the presence of various number of parameters as maximum number of possible connections and equals to 10 , the original AODV performing well than the AODV-DOR, but when the the maximum number of possible network connections is greater than or equals to 20 than AODV-DOR is performing well than original AODV as shown in table 2. This concept will helps researchers to select the different form of AODV according to the availability of maximum number of network connections. The simulation result shows the difference between the performance of the original AODV and AODV-DOR routing protocol in term of average end to end delay and pause time.

\section{ACKNOWLEDGMENTS}

Shyam Singh Rajput received Bachelor degree in Comuter Science \& Engineering from RGPV University, Bhopal, India, in 2011. He is pursuing M.Tech in CSE from ABVIIITM,Gwalior,M.P , India. His research interest includes ad hoc and sensor networks, information security.

Vinod Kumar received Bachelor degree in Information Technology from GBTU University, Lucknow, India, in 2010. He is pursuing M.Tech in CSE from ABVIIITM,Gwalior,M.P , India. His research interest includes ad hoc and cloud computing, information security.

Kalka Dubey received Bachelor degree in Comuter Science \& Engineering from MITS, Gwalior, India, in 2010. He is pursuing M.Tech in CSE from ABV-IIITM,Gwalior,M.P , India. His research interest includes ad hoc and cloud computing, information security.

\section{REFERENCES}

[1] A. Boukerche, "A Simulation Based Study of OnDemand Routing Protocols for Ad hoc Wireless Networks", Proceedings 34th Annual Simulation Symposium (SS 2001), Seattle, WA, USA, 22-26 April 2001, pp. 85-92. 
[2] Xiaoyan Hong, Kaixin Xu and Mario Gerla, "Scalable routing protocols for mobile ad hoc networks", 2002.

[3] S. A. Ade and P.A.Tijare, "Performance Comparison of AODV, DSDV, OLSR and DSR Routing Protocols in Mobile Ad Hoc Networks", July-December 2010, Volume 2,No. 2, pp. 545-548

[4] Sapna S. Kaushik and P.R.Deshmukh, "Comparison of effectiveness of AODV, DSDV and DSR routing protocols in MANETs", International Journal of Information Technology and Knowledge management, July-December 2009, Volume 2, No. 2, pp. 499-502.

[5] C. E. Perkins and P. Bhagwat, "Highly dynamic destination-sequenced distance vector routing (DSDV) for mobile computers", Proceedings of ACM SIGCOMM 94, 1994, pp. 34-244.

[6] Nor Surayati Mohamad Usop, Azizol Abdullah and Ahmad Faisal Amri Abidin, "Performance Evaluation of AODV, DSDV \& DSR Routing Protocol in Grid Environment", IJCSNS International Journal of Computer Science and Network Security, VOL.9 No.7, July 2009, pp. $261-268$.

[7] Perkins C., Belding-Royer and E. Das, "Ad-hoc ondemand distance vector (aodv) routing", rfc-3561, network working group (July 2003).
[8] Perkins, C.E., Royer and E.M, "Ad hoc on-demand distance vector (aodv) routing", In Proceeding of IEEE Workshop on Mobile Computing system and applications. pp. 90-100 (February 1999).

[9] The Network Simulator NS-2 tutorial homepage, http://www.isi.edu/nsnam/ns/tutorial/index.html.

[10]Rendong Bai and Mukesh Singhal,"DOA: DSR over AODV Routing for Mobile Ad Hoc Networks",IEEE Transaction on Mobile Computing,Vol. 5,No. 10,Otober 2006

[11] R.S. Al-Qassas, A. Al-Ayyoub and M. OuldKhaoua,"Bandwidth-efficient routing protocol for mobile ad hoc networks",IEE Proc.-Softw., Vol. 150, No. 4, August 2003

[12] Joo-Han Song, Vincent W. S. Wong, and Victor C. M. Leung,"Efficient On-Demand Routing for Mobile Ad Hoc Wireless Access Networks",IEEE Journal on Selected Areas in Communications, Vol. 22, No. 7, September 2004 